\title{
Trends and Updated Statistics of Lung Cancer in Korea
}

\author{
Chan Kwon Park, M.D., Ph.D. ${ }^{1,2}$ and Seung Joon Kim, M.D., Ph.D. ${ }^{1,2}$ \\ ${ }^{1}$ Division of Pulmonology, Department of Internal Medicine, ${ }^{2}$ The Cancer Research Institute, College of Medicine, The Catholic \\ University of Korea, Seoul, Korea
}

The clinical characteristics and prognostic factors of patients with lung cancer are expected to differ with respect to geographical differences from the past to the future. In the Republic of Korea, a few national lung cancer surveys have been conducted.

In 1997, Lee et al. ${ }^{1}$ performed the first survey. Among 3,794 patients, they found that the most frequent symptom was cough (57.2\%), and asymptomatic patients accounted for only $7.2 \%$ of all patients. Smokers, including current and ex-smokers, accounted for $76.5 \%$ (89.8\% male and $25.4 \%$ female). Considering the high smoking rate, it is reasonable to think that the tumor was mainly located in the central lung region, and the major results of histopathological assessment were squamous cell carcinoma (44.7\%) and small cell cancer (16.8\%). Therefore, the principal diagnostic tool was bronchoscopic biopsy. In contrast, percutaneous needle biopsy was the main tool for the diagnosis of adenocarcinoma (27.9\%), which usually occurred in the peripheral lung region. Advanced stages IIIB and IV disease were detected in $65.3 \%$ of patients with non-small cell lung cancer (NSCLC).

In 2005, In et $\mathrm{al}^{2}{ }^{2}$ performed the second survey. Among the total of 8,788 patients, they found that cough (38.1\%) was still the most frequent symptom, and $6.5 \%$ of the patients had no subjective symptoms. These asymptomatic patients were of

\footnotetext{
Address for correspondence: Seung Joon Kim, M.D., Ph.D.

Division of Pulmonology, Department of Internal Medicine, Seoul St. Mary's Hospital, The Cancer Research Institute, College of Medicine, The Catholic University of Korea, 222 Banpo-daero, Seocho-gu, Seoul 06591, Korea

Phone: 82-2-2258-6063, Fax: 82-2-599-3589

E-mail: cmcksj@catholic.ac.kr

Received: Feb. 23, 2019

Revised: Mar. 4, 2019

Accepted: Mar. 8, 2019

@) It is identical to the Creative Commons Attribution Non-Commercial License (http://creativecommons.org/licenses/by-nc/4.0/).
}

younger age, more often female, non-smokers, and more commonly had adenocarcinoma. These asymptomatic patients displayed significantly better prognosis from NSCLC as they exhibited earlier stage of disease (stage I-II, 61.3\%; stage III, $22.1 \%$; and stage IV, 16.6\%) than symptomatic patients (stage I-II, 22.3\%; stage III, 35.4\%; and stage IV, 42.4\%). Sixty percent of asymptomatic patients could undergo surgery, whereas only $19.3 \%$ of symptomatic patients could undergo surgical treatment.

In et al. ${ }^{2}$ also reported that $40.5 \%$ of the patients were current smokers, followed by $30.6 \%$ former smokers and $28.9 \%$ never-smokers, whereas only $20.3 \%$ of female patients with lung cancer had a smoking history. Compared to the results of the first national survey, the proportion of female patients with lung cancer increased from $20.7 \%$ to $24.2 \%$, and the incidence of never-smokers also increased from $23.5 \%$ to $28.9 \%^{3}$.

In contrast to the results of the first national survey, adenocarcinoma $(36.1 \%)$ was the most common result of histopathological assessment, followed by squamous cell carcinoma (32.1\%) and small cell carcinoma (13.5\%). The leading histopathologic subtype had changed from squamous cell carcinoma to adenocarcinoma.

Shin et al. ${ }^{4}$ obtained data from the Korea Central Cancer Registry (1999-2012) and Statistics Korea (1983-2013). They reported that the Korean lung cancer mortality began to decrease in 2002. Among patients diagnosed between 19931997 and 2008-2012, the overall 5-year relative survival rates improved significantly from $11.2 \%$ to $19.3 \%$ in men and $14.7 \%$ to $28.2 \%$ in women, respectively.

Recently, Kim et al. ${ }^{5}$ conducted a pilot study using data of the Korean nationwide lung cancer registry. Among the 23,254 new patients with lung cancer enrolled in the Korea Central Cancer Registry in 2013, a total of 489 patients from 19 hospitals were evaluated in terms of clinical characteristics, histopathology, and prognostic factors. The clinical data including age, sex, body mass index, smoking history, symptoms, performance status, histopathologic type, clinical staging, epidermal growth factor receptor (EGFR) mutation status, initial treatment modality, and survival status were retrospectively analyzed until December 2015. They found that the 
characteristics in Korean patients with lung cancer changed compared to those found in the previous two national lung cancer surveys. Lung cancer in Korea occurred predominantly in elderly patients, and the proportion of patients with adenocarcinoma (48.7\%) further increased compared with those in the first survey in 1997 (27.9\%) and second survey in $2005(36.1 \%)^{3}$. They indicated that poor prognosis was exhibited by patients who were older, ever-smokers, malnourished, untreated, and advanced stage. They also identified that $13.1 \%$ of patients were asymptomatic and showed good prognosis in terms of mortality (hazard ratio, 0.265 ), which was compatible with the results of the second survey in 2005.

According to the Korean Statistical Information Service, lung cancer deaths in the Korean population have been increasing in both men and women since the early 1980s. Among the total of 17,980 deaths due to lung cancer in 2017, men accounted for 13,272 and women accounted for 4,708. Of a total of 24,267 incidences of lung cancer in 2015, men accounted for 17,015 and women accounted for 7,252. The never-smoker lung cancer incidence was estimated to increase in Korea $^{6}$. Considering that the lung cancer incidence in Korean women was 3,592 in 2000, it increased by more than 2 -fold in 15 years. However, after age-standardized adjustment, the lung cancer incidence has recently been decreasing in both men and women ${ }^{7}$. The reason for the decreasing incidence after the age adjustment could be growth in the Korean elderly population. In the United States, Henley et al. ${ }^{8}$ demonstrated that the female lung cancer incidence rate in 2015 increased with age, with the highest rate in those aged $75-79$ years. Secondhand smoke, radon gas, air pollution, cooking oil fume, occupational exposure, and female sex hormones were regarded as risk factors of lung cancer ${ }^{9-15}$.

The Korean Statistical Information Service indicated that the smoking rate in Korean women was $6.4 \%$ in 2016, which has remained stable since 1998 . The passive smoking rate in non-smoking women was $7.9 \%$ in 2016, which has been decreasing since 2005. According to epidemiological, clinical, and biological characteristics, lung cancer in never-smokers is a different disease from lung cancer in smokers ${ }^{16}$.

A study from the Korean Association for Lung Cancer in 2014 investigated 743 of a total of 7,355 Korean female patients with lung cancer. Most Korean women who developed lung cancer in 2014 were never-smokers (87.6\%). According to smoking status, female lung cancer characteristics such as symptoms, stage, histopathology, EGFR mutation positivity, and initial treatment modality were significantly different. Never-smoker female patients with lung cancer showed an increase in asymptomatic disease, stage I lung cancer, histology of adenocarcinoma, EGFR mutation positivity, and curative resection compared to ever-smoker female patients.

There are also trends in survival as well as in prognostic factor. Park and Jang ${ }^{6}$ indicated that the 5-year relative survival rate has increased from $11.3 \%$ (1993-1995) to $21.9 \%$ (2008-
2012). Furthermore, 10-year relative survival reached at $12.6 \%$ in 2001-2005. Absence of symptom at the initial diagnosis is an unchanged good prognostic factor between 2005 and $2013^{2,5}$

In conclusion, the trends in epidemiology and clinical characteristics of lung cancer in Korea have changed over time. Further research is needed to guide patient management, as well as future therapeutic strategies for lung cancer.

\section{Conflicts of Interest}

No potential conflict of interest relevant to this article was reported.

\section{References}

1. Lee C, Kang KH, Koh Y, Chang J, Chung HS, Park SK, et al. Characteristics of lung cancer in Korea, 1997. Lung Cancer 2000;30:15-22.

2. In KH, Kwon YS, Oh IJ, Kim KS, Jung MH, Lee KH, et al. Lung cancer patients who are asymptomatic at diagnosis show favorable prognosis: a Korean Lung Cancer Registry Study. Lung Cancer 2009;64:232-7.

3. Kim YC, Won YJ. The development of the Korean Lung Cancer Registry (KALC-R). Tuberc Respir Dis 2019;82:91-3.

4. Shin A, Oh CM, Kim BW, Woo H, Won YJ, Lee JS. Lung cancer epidemiology in Korea. Cancer Res Treat 2017;49:616-26.

5. Kim HC, Jung CY, Cho DG, Jeon JH, Lee JE, Ahn JS, et al. Clinical characteristics and prognostic factors of lung cancer in Korea: a pilot study of data from the Korean nationwide lung cancer registry. Tuberc Respir Dis 2019;82:118-25.

6. Park JY, Jang SH. Epidemiology of lung cancer in Korea: recent trends. Tuberc Respir Dis 2016;79:58-69.

7. Jung KW, Won YJ, Kong HJ, Lee ES; Community of Population-Based Regional Cancer Registries. Cancer statistics in Korea: incidence, mortality, survival, and prevalence in 2015. Cancer Res Treat 2018;50:303-16.

8. Henley SJ, Gallaway S, Singh SD, O’Neil ME, Buchanan Lunsford N, Momin B, et al. Lung cancer among women in the United States. J Womens Health (Larchmt) 2018;27:1307-16.

9. Bonner MR, Bennett WP, Xiong W, Lan Q, Brownson RC, Harris CC, et al. Radon, secondhand smoke, glutathione-Stransferase M1 and lung cancer among women. Int J Cancer 2006;119:1462-7.

10. Ahn YS, Kang SK. Asbestos-related occupational cancers compensated under the Industrial Accident Compensation Insurance in Korea. Ind Health 2009;47:113-22.

11. Chakraborty S, Ganti AK, Marr A, Batra SK. Lung cancer in women: role of estrogens. Expert Rev Respir Med 2010;4:50918.

12. Silveyra P, Floros J. Air pollution and epigenetics: effects on 
SP-A and innate host defence in the lung. Swiss Med Wkly 2012;142:w13579.

13. Kim CH, Lee YC, Hung RJ, McNallan SR, Cote ML, Lim WY, et al. Exposure to secondhand tobacco smoke and lung cancer by histological type: a pooled analysis of the International Lung Cancer Consortium (ILCCO). Int J Cancer 2014;135:1918-30.

14. Paris C, Do P, Mastroianni B, Dixmier A, Dumont P, Pichon
E, et al. Association between lung cancer somatic mutations and occupational exposure in never-smokers. Eur Respir J 2017;50:1700716.

15. Jia PL, Zhang C, Yu JJ, Xu C, Tang L, Sun X. The risk of lung cancer among cooking adults: a meta-analysis of 23 observational studies. J Cancer Res Clin Oncol 2018;144:229-40.

16. Sun S, Schiller JH, Gazdar AF. Lung cancer in never smokers: a different disease. Nat Rev Cancer 2007;7:778-90. 